\title{
A Simple Method for Amateur Investors to Analyze Covered Call Options
}

\author{
Greg Samsa, PhD \\ Duke Department of Biostatistics and Bioinformatics, \\ 11084 Hock Plaza, Durham NC 27510, USA.
}

\begin{abstract}
We describe a simple method which amateur investors can use to analyze covered calls. The most basic version is based on the formula for the expectation of a truncated Gaussian distribution, and it can be generalized to accommodate other assumptions. This approach might be especially considered during a time of market overvaluation, such as the present. During such times, investors should shift their preferences toward writing deep-in-the-money covered calls, which provide a greater margin of safety while monetizing the (probably optimistic) expectations of other market participants regarding future returns.
\end{abstract}

Keywords: Option pricing theory, truncated Gaussian distribution

\section{INTRODUCTION}

Investors' approaches to option pricing extends from formal and highly quantitative to informal and qualitative. Professional traders base option pricing on implied volatility, which in turn is estimated using complex mathematical models such as Black-Scholes [1]. Amateur investors tend to conceptualize things differently, such as "I'd like to protect my position at modest cost and so will buy a put option somewhere below the market", "I'd like to gamble on a take-over bid and so will buy an out-of-the-money call option", and "I have no intention of selling a stock unless it rises in price significantly but notice that the option premiums are high - perhaps I should write a covered call". For them, whatever mathematical analysis is performed is subservient to other considerations.

Here, we illustrate a simple heuristic approach that amateur investors could potentially use to analyze covered calls.

\section{METHODS}

We assume that an amateur investor is considering a "buy-write", whereby they buy stock and then write a covered call option on that same stock position. We make a number of assumptions in the spirit of simplification and concreteness:

- The option will be held until expiration (and thus can be treated as if it is a European option).

- The duration of the option is approximately 12 months (and so no effort is required to annualize returns).

- Dividend payments are received at the time the option is written (potentially discounted to reflect their uncertainty and the time value of money).

- The investor receives the "bid" price for writing the option (although in practice they often receive a figure between the bid and asked price).

- The distribution of the future price is Gaussian (although this assumption can be relaxed). 
Denote the current stock price by $\mathrm{X}_{0}$, denote the future stock price at the option's expiration date by $\mathrm{X}_{1}$, and assume for simplicity that the distribution of $\mathrm{X}_{1}$ is Gaussian with parameters $\mu$ (from which the expected return is derived) and $\sigma$ (from which the risk is derived). Denote the strike price by $\mathrm{S}$. In other words, the call writer cedes to the option purchaser any gain in $\mathrm{X}_{1}$ above $\mathrm{S}$.

The call option induces a truncated Gaussian distribution, truncated at $S$. The expected value of this truncated distribution is known to be $E\left(X_{1} \mid X_{1}<S\right)=\mu-\left[\sigma \varphi\left(S^{*}\right) / \Phi\left(S^{*}\right)\right]$, where $S^{*}=(S$ $\mu) / \sigma$, that is the distance from the strike price to $\mu$ in standard deviation units, and $\varphi\left(^{*}\right)$ and $\Phi\left(^{*}\right)$ are the probability density and cumulative density functions of the standard Gaussian distribution, respectively [2].

At time 1, the investor will either be required to sell the stock for $S$ (i.e., if $X_{1}>S$ ) or will retain the stock (i.e., if $X_{1}<S$ ). The probability of these events occurring are 1- $\Phi\left(^{*}\right)$ and $\Phi\left(^{*}\right.$ ), respectively. If $X_{1}>S$ the investor will earn a maximum profit. If $X_{1}$ falls sufficiently far below $S$ the investor will suffer an unrealized loss.

The expected value of the investor's holding at the time of expiration is $E\left(X_{1}\right)=\left[\left(1-\Phi\left(^{*}\right)\right) S\right]+$ $\left.\left[\Phi\left(^{*}\right)\right) \mathrm{E}\left(\mathrm{X}_{1} \mid \mathrm{X}_{1}<\mathrm{S}\right)\right]$, with the conditional expectation defined as above. Thus, the expected value of the investment is $\mathrm{E}\left(\mathrm{X}_{1}\right)$, plus the option premium plus any dividends received, minus the purchase price. $\left.\mathrm{E}\left(\mathrm{X}_{1} \mid \mathrm{X}_{1}<\mathrm{S}\right)\right]$ is always less than $\mathrm{E}\left(\mathrm{X}_{1}\right)$, and the investor expects the option premium and dividends to more than make up for this difference.

Both $\mathrm{E}\left(\mathrm{X}_{1} \mid \mathrm{X}_{1}<\mathrm{S}\right)$ and $\mathrm{E}\left(\mathrm{X}_{1}\right)$ are functions of two variables only: $\mu$ and $\sigma$, which the investor must specify. To derive $\mu$, the investor can rely on the efficient market hypothesis [3] that (loosely speaking) the current price $\mathrm{X}_{0}$ correctly reflects all available information. To obtain the expected annual return of the stock in question, begin with the historical return of the market as a whole (i.e., $10-12 \%$, depending upon how the calculation is made) and then adjust by the relative volatility of the stock in comparison with the market (i.e., "beta"). For example, if $\beta=1$ then $\mu$ could be $X_{0}^{*} 1.10$. To derive $\sigma$, the investor specifies a value below which $X_{1}$ is very unlikely to fall. This value can be based upon both economic considerations (e.g., enterprise value, price-earnings ratio, dividend yield), historical considerations, or both. Then, $\sigma$ is derived as the half-width of the interval between that value and $\mu$.

\section{EXAMPLES}

We consider two stocks. At the time of this writing, Mylan Laboratories (MYL) has a stock price of $\$ 19.61$ and pays no dividend. We set $\mu=21$ and $\sigma=2.5$. Setting $\mu=21$ anticipates that MYL will only increase in price by $7.1 \%$, and thus is mildly conservative. Furthermore, we assume that $\mathrm{X}_{1}$ is very unlikely to fall below 16 , thus implying that $\sigma=2.5$.

At the time of this writing, L Brands (LB) has a stock price of $\$ 18.33$ and pays a quarterly dividend of $\$ 0.30$. We set $\mu=18$ and $\sigma=2.5$. The annual dividend yield is in excess of $6 \%$, and we conservatively postulate that the entire return will be based upon the dividend and, indeed, the stock price will fall slightly. We assume, primarily based on the floor implied by the dividend, that it is very unlikely for $\mathrm{X}_{1}$ to fall below 13.33, implying that $\sigma=2.5$. In other words, we implicitly assume that LB will neither go bankrupt nor cut its dividend, and that regardless of changes in interest rates during the next 12 months the dividend yield will remain in a range that would make LB attractive to dividend-seeking investors. 
Without attempting a comprehensive analysis, MYL and LB have been performing poorly, both as companies and as stocks. Investor optimism is in short supply. Concerns about these companies are real, but presumed to already be embedded within their current stock prices.

Table 1 summarizes various potential call options which could be written on MYL. Row 4 summarizes the calculations for a strike price of 17.50 (column 1). The option premium is 4.65 (column 2), which discounts the purchase price to $19.61-4.65=14.96$ (column 3). The option premium of 4.65 can be divided into 2.11 of intrinsic value (column 4) and 2.54 in time value (column 5). The maximum profit is 2.54 (column 6), which will be obtained if $X_{1}>17.50$. The strike price of $S=17.50$ is 0.84 standard deviations below $\mu=21$ (column 7 ), which forms the basis for the expected value calculations. $\mathrm{X}_{1}$ is anticipated to be above $17.5080 .1 \%$ of the time (column 8). The expected value of the truncated distribution is 17.50 (column 9), and the expected profit is 1.61 (column 10). The maximum possible return is $2.54 / 14.96=16.98 \%$ (column 11), and the expected return is $1.61 / 14.96=10.78 \%$ (column 12 ).

Assuming that the option is held until expiration, the investor will receive the time value, which exceeds $10 \%$ of the purchase price for those "near-the-money options" whose strike prices are near the current price (i.e., $S=17.50,20.00$ and 22.50). For those three options, the maximum returns range from $17.0-31.3 \%$, all of which would presumably be acceptable to a typical investor. Expected returns range from 8-0-10.8\%, all of which modestly exceed the hypothesized $7.1 \%$ return in the absence of writing the option.

The intrinsic value of the options can be considered to be their "margin of safety", in that it is the amount that MYL can drop and still have the investor receive the maximum possible return. For the "deep-in-the-money" $S=10.00$ and 12.50, their margin of safety implies that the investor will almost always receive the maximum possible return. At the other end of the spectrum, the "far-out-of-the-money" options $S=27.50,30.00,32.50$ and 35.00 will almost never be exercised, and the investor pockets a small premium "for free" (although they can't sell the underlying stock without first unwinding the option).

For a typical covered call writer, the most reasonable choices are the near-the-money options with $S=15.00,17.50,20.00,22.50$ and 25.00. A pessimistic approach might select $S=15.00$, for a maximum $11.4 \%$ return with $96.7 \%$ probability (implied by the margin of safety of 4.61 ). An ambivalent approach might select $S=17.50$ or $S=20.00$, the former having the largest expected return, and the latter having the maximum amount of time value and a maximum return of $23.8 \%$. An optimistic approach might select $S=22.50$ or $S=25.00$, both of which collect a significant time value premium while retaining maximum returns in excess of $30 \%$.

Table 1: MYL, current price=19.61, expected dividends=0, $\mathbf{m u}=21$, sigma=2.5

\begin{tabular}{|c|c|c|c|c|c|c|c|c|c|c|c|}
\hline $\begin{array}{l}\text { Strike } \\
\text { price }\end{array}$ & $\begin{array}{l}\text { Call } \\
\text { premium }\end{array}$ & $\begin{array}{l}\text { Discounted } \\
\text { price }\end{array}$ & $\begin{array}{l}\text { intrinsic } \\
\text { value }\end{array}$ & $\begin{array}{l}\text { time } \\
\text { value }\end{array}$ & $\begin{array}{l}\text { maximum } \\
\text { profit }\end{array}$ & $\begin{array}{l}\text { s.d. } \\
\text { multiple }\end{array}$ & $\begin{array}{l}\text { exercise } \\
\text { probability }\end{array}$ & $\begin{array}{l}\text { expected } \\
\text { value } \\
\text { truncated }\end{array}$ & $\begin{array}{l}\text { expected } \\
\text { return }\end{array}$ & $\begin{array}{l}\max \\
\text { return } \\
(\%)\end{array}$ & $\begin{array}{l}\text { expected } \\
\text { return } \\
(\%)\end{array}$ \\
\hline 10.00 & 9.90 & 9.71 & 9.61 & 0.29 & 0.29 & -3.84 & $>.999$ & 10.81 & 0.29 & 2.99 & 2.98 \\
\hline 12.50 & 7.95 & 11.66 & 7.11 & 0.84 & 0.84 & -2.84 & .998 & 13.15 & 0.82 & 7.20 & 7.06 \\
\hline 15.00 & 6.15 & 13.46 & 4.61 & 1.54 & 1.54 & -1.84 & .967 & 15.41 & 1.35 & 11.44 & 10.05 \\
\hline 17.50 & 4.65 & 14.96 & 2.11 & 2.54 & 2.54 & -0.84 & .801 & 17.50 & 1.61 & 16.98 & 10.78 \\
\hline 20.00 & 3.45 & 16.16 & 0 & 3.45 & 3.84 & 0.16 & .438 & 19.25 & 1.48 & 23.76 & 9.15 \\
\hline 22.50 & 2.48 & 17.13 & 0 & 2.48 & 5.37 & 1.16 & .124 & 20.42 & 1.37 & 31.35 & 8.01 \\
\hline 25.00 & 1.74 & 17.87 & 0 & 1.74 & 7.13 & 2.16 & .016 & 20.90 & 1.38 & 39.90 & 7.73 \\
\hline 27.50 & 1.20 & 18.41 & 0 & 1.20 & 9.09 & 3.16 & .001 & 20.99 & 1.39 & 49.38 & 7.55 \\
\hline 30.00 & 0.81 & 18.805 & 0 & 0.81 & 11.20 & 4.16 & $>.001$ & 21.00 & 1.39 & 59.57 & 7.39 \\
\hline 32.50 & 0.56 & 19.05 & 0 & 0.56 & 13.45 & 5.16 & $>.001$ & 21.00 & 1.39 & 70.60 & 7.30 \\
\hline 35.00 & 0.37 & 19.24 & 0 & 0.37 & 15.76 & 6.16 & $>.001$ & 21.00 & 1.39 & 81.91 & 7.22 \\
\hline
\end{tabular}


Table 2 presents a similar summary for LB. Expected returns now include the anticipated 1.20 in dividends. The most favorable risk-return appears to hold for low strike prices - for example, for $S=10.00$ and $S=12.50$ the expected returns are in the range of $16-17 \%$, and the probability of achieving the maximum possible return is at least $99 \%$. There, returns are modest on an absolute scale, but are increased on a relative scale because of the deep discounting of the purchase price. For example, discounting the purchase price from 18.33 to 9.63 almost doubles the effective dividend yield. If the investor concludes that the option market is suggesting that LB's dividends are at significant risk a sensitivity analysis could be performed which discounts those dividends to a value of less than 1.20.

Excellent possible returns are also available for $S=15.00$, leaving open the possibility of somewhat greater maximum returns than for $S=10.00$ and 12.50 , but at the cost of increasing the likelihood that the investor will be holding stock in LB after the option expires.

Table 2: LB, current price=18.33, expected dividends=1.20, $\mathbf{m u = 1 8 , ~ s i g m a = 2 . 5}$

\begin{tabular}{|c|c|c|c|c|c|c|c|c|c|c|c|}
\hline $\begin{array}{l}\text { Strike } \\
\text { price }\end{array}$ & $\begin{array}{l}\text { Call } \\
\text { premium }\end{array}$ & $\begin{array}{l}\text { Discounted } \\
\text { price }\end{array}$ & $\begin{array}{l}\text { intrinsic } \\
\text { value }\end{array}$ & $\begin{array}{l}\text { time } \\
\text { value }\end{array}$ & $\begin{array}{l}\text { maximum } \\
\text { profit }\end{array}$ & $\begin{array}{l}\text { s.d. } \\
\text { multiple }\end{array}$ & $\begin{array}{l}\text { exercise } \\
\text { probability }\end{array}$ & $\begin{array}{l}\text { expected } \\
\text { value } \\
\text { truncated }\end{array}$ & $\begin{array}{l}\text { expected } \\
\text { return }\end{array}$ & $\begin{array}{l}\max \\
\text { return } \\
(\%)\end{array}$ & $\begin{array}{l}\text { expected } \\
\text { return } \\
(\%)\end{array}$ \\
\hline 10.00 & 8.70 & 9.63 & 8.33 & 0.37 & 1.57 & -3.33 & $>.999$ & 9.02 & 1.57 & 16.30 & 16.26 \\
\hline 12.50 & 6.70 & 11.63 & 5.83 & 0.87 & 2.07 & -2.33 & .990 & 11.32 & 1.99 & 17.80 & 17.13 \\
\hline 15.00 & 5.10 & 13.23 & 3.33 & 1.77 & 2.97 & -1.33 & .909 & 13.51 & 2.37 & 22.45 & 17.89 \\
\hline 17.50 & 3.90 & 14.43 & 0.83 & 3.07 & 4.27 & -0.33 & .630 & 15.45 & 2.07 & 29.59 & 14.33 \\
\hline 20.00 & 2.75 & 15.58 & 0 & 2.75 & 5.62 & 0.67 & .252 & 16.93 & 1.27 & 36.07 & 8.15 \\
\hline 22.50 & 1.80 & 16.53 & 0 & 1.80 & 7.17 & 1.67 & .048 & 17.74 & 0.92 & 43.38 & 5.58 \\
\hline 25.00 & 1.40 & 16.93 & 0 & 1.40 & 2.67 & 2.67 & .004 & 17.97 & 0.87 & 54.75 & 5.16 \\
\hline 27.50 & 1.00 & 17.33 & 0 & 1.00 & 3.67 & 3.67 & $>.001$ & 18.00 & 0.87 & 65.61 & 5.02 \\
\hline 30.00 & 0.70 & 17.63 & 0 & 0.70 & 4.67 & 4.67 & $>.001$ & 18.00 & 0.87 & 76.97 & 4.93 \\
\hline 32.50 & 0.45 & 17.88 & 0 & 0.45 & 5.67 & 5.67 & $>.001$ & 18.00 & 0.87 & 88.48 & 4.87 \\
\hline 35.00 & 0.30 & 18.03 & 0 & 0.30 & 6.67 & 6.67 & $>.001$ & 18.00 & 0.87 & 100.80 & 4.83 \\
\hline
\end{tabular}

\section{EXTENSION}

This approach can be straightforwardly generalized. For example, Table 3 illustrates how the expected value calculation can be performed directly. We continue to assume that $\mu=21$. We also assume that $\mathrm{X}_{1}$ is Gaussian with $\sigma=2.5$ below the mean (i.e., an assumption which might be made by the call writer) and with $\sigma=5.0$ above the mean (i.e., an assumption which might be made by the call buyer). Possible values of $\mathrm{X}_{1}$ are divided into 100 bins, each bin containing $1 \%$ percent of the mass. For example, as per the standardized Gaussian distribution, the bin with the smallest $1 \%$ of possible values has the standardized value of -2.58 at its' midpoint. This is translated into a quantile value of $21+(-2.58)(2.5)=14.56$. Similarly, the bin with the largest $1 \%$ of possible values has the standardized value of 2.58 at its' midpoint. This translates into a quantile value of $21+(2.58)(5.0)=33.88$.

The expected value of the non-truncated distribution is calculated in straightforward fashion as $\Sigma\left(\mathrm{W}_{\mathrm{i}} \mathrm{X}_{\mathrm{i}}\right)$, where $\mathrm{W}_{\mathrm{i}}$ is the probability of falling into the bin (here, 0.01 for each bin). The expected value of the truncated distribution is calculated in analogous fashion, using only those bins with $\mathrm{X}_{1}<\mathrm{S}$, and normalizing the weights to add to 1 . For example, $\mathrm{E}\left(\mathrm{X}_{1} \mid \mathrm{X}_{1}<15.57\right)=15.07$ is the average of 14.56 (from bin 1) and 15.57 (from bin 2).

This approach does not require assuming that the distribution of $\mathrm{X}_{1}$ is Gaussian. Indeed, the distribution in question can be log-normal (or any other distribution) if desired - all that is needed is to specify the cumulative distribution function. If the investor wishes to allow for the possibility of bankruptcy during the follow-up interval this can be accomplished by creating a bin with $\mathrm{X}_{1}=0$ and a non-zero probability of occurrence and then performing the expected value calculation in the usual fashion. 
Table 3: Illustration of alternative calculation method, $\mathrm{mu}=21$, sigma $=2.5$ (lower), sigma $=\mathbf{5 . 0}$ (upper)

\begin{tabular}{|l|l|l|l|l|}
\hline$\left.\Phi{ }^{*}\right)$ & quantile & quantile & $\mathrm{E}\left(\mathrm{X}_{1} \mid \mathrm{X}_{1}<\mathrm{S}\right)$ & $\mathrm{E}\left(\mathrm{X}_{1}\right)$ \\
\hline 0.005 & -2.58 & 14.56 & 14.56 & 14.56 \\
\hline 0.015 & -2.1 & 15.57 & 15.07 & 15.08 \\
\hline 0.025 & -1.96 & 16.10 & 15.41 & 15.43 \\
\hline 0.035 & -1.81 & 16.47 & 15.68 & 15.70 \\
\hline 0.045 & -1.70 & 16.76 & 15.89 & 15.93 \\
\hline 0.055 & -1.60 & 17.00 & 16.08 & 16.13 \\
\hline 0.065 & -1.51 & 17.21 & 16.24 & 16.30 \\
\hline 0.075 & -1.44 & 17.40 & 16.39 & 16.46 \\
\hline 0.085 & -1.37 & 17.57 & 16.52 & 16.61 \\
\hline 0.095 & -1.31 & 17.72 & 16.64 & 16.74 \\
\hline 0.105 & -1.25 & 17.87 & 16.75 & 16.87 \\
\hline 0.115 & -1.20 & 18.00 & 16.85 & 16.99 \\
\hline 0.125 & -1.15 & 18.12 & 16.95 & 17.10 \\
\hline 0.135 & -1.10 & 18.24 & 17.04 & 17.21 \\
\hline 0.145 & -1.06 & 18.35 & 17.13 & 17.31 \\
\hline 0.155 & -1.02 & 18.46 & 17.21 & 17.41 \\
\hline 0.165 & -0.97 & 18.56 & 17.29 & 17.50 \\
\hline 0.175 & -0.93 & 18.66 & 17.37 & 17.60 \\
\hline 0.185 & -0.90 & 18.76 & 17.44 & 17.69 \\
\hline 0.195 & -0.86 & 18.85 & 17.51 & 17.77 \\
\hline 0.205 & -.082 & 18.94 & 17.58 & 17.86 \\
\hline 0.215 & -0.79 & 19.03 & 17.65 & 17.94 \\
\hline 0.225 & -.076 & 19.11 & 17.71 & 18.03 \\
\hline 0.235 & -0.72 & 19.19 & 17.77 & 18.11 \\
\hline 0.245 & -0.69 & 19.27 & 17.83 & 18.19 \\
\hline 0.255 & -0.66 & 19.35 & 17.89 & 18.26 \\
\hline 0.265 & -0.63 & 19.43 & 17.95 & 18.34 \\
\hline 0.275 & -0.60 & 19.51 & 18.00 & 18.42 \\
\hline 0.285 & -0.57 & 19.58 & 18.06 & 18.49 \\
\hline 0.295 & -0.54 & 19.65 & 18.11 & 18.57 \\
\hline 0.305 & -0.51 & 19.72 & 18.16 & 18.64 \\
\hline 0.315 & -0.48 & 19.80 & 18.21 & 18.71 \\
\hline 0.325 & -0.45 & 19.87 & 18.26 & 18.78 \\
\hline 0.335 & -0.43 & 19.93 & 18.31 & 18.86 \\
\hline 0.345 & -0.40 & 20.00 & 18.36 & 18.93 \\
\hline 0.355 & -0.37 & 20.07 & 18.41 & 19.00 \\
\hline 0.365 & -0.35 & 20.14 & 18.46 & 19.07 \\
\hline 0.375 & -0.32 & 20.20 & 18.50 & 19.14 \\
\hline 0.385 & -0.29 & 20.27 & 18.55 & 19.21 \\
\hline 0.395 & -0.27 & 20.33 & 18.59 & 19.28 \\
\hline 0.405 & -0.24 & 20.40 & 18.64 & 19.35 \\
\hline 0.415 & -0.21 & 20.46 & 18.68 & 19.42 \\
\hline 0.425 & -0.19 & 20.53 & 18.72 & 19.49 \\
\hline 0.435 & -0.16 & 20.59 & 18.76 & 19.56 \\
\hline 0.445 & -0.14 & 20.65 & 18.81 & 19.63 \\
\hline 0.455 & -0.11 & 20.72 & 18.85 & 19.70 \\
\hline 0.465 & -0.09 & 20.78 & 18.89 & 19.77 \\
\hline 0.475 & -0.06 & 20.84 & 18.93 & 19.84 \\
\hline 0.485 & -0.04 & 20.91 & 18.97 & 19.91 \\
\hline 0.495 & -0.01 & 20.97 & 19.01 & 19.98 \\
\hline 0.505 & 0.01 & 21.06 & 19.05 & 20.07 \\
\hline 0.515 & 0.04 & 21.19 & 19.09 & 20.17 \\
\hline 0.525 & 0.06 & 21.31 & 19.13 & 20.28 \\
\hline 0.535 & 0.09 & 21.44 & 19.18 & 20.39 \\
\hline 0.545 & 0.11 & 21.57 & 19.22 & 20.50 \\
\hline & & & & \\
\hline & & & & \\
\hline
\end{tabular}




\begin{tabular}{|l|l|l|l|l|}
\hline 0.555 & 0.14 & 21.69 & 19.26 & 20.61 \\
\hline 0.565 & 0.16 & 21.82 & 19.31 & 20.73 \\
\hline 0.575 & 0.19 & 21.95 & 19.35 & 20.84 \\
\hline 0.585 & 0.21 & 22.07 & 19.40 & 20.96 \\
\hline 0.595 & 0.24 & 22.20 & 19.45 & 21.09 \\
\hline 0.605 & 0.27 & 22.33 & 19.49 & 21.21 \\
\hline 0.615 & 0.29 & 22.46 & 19.54 & 21.34 \\
\hline 0.625 & 0.32 & 22.59 & 19.59 & 21.47 \\
\hline 0.635 & 0.35 & 22.73 & 19.64 & 21.60 \\
\hline 0.645 & 0.37 & 22.86 & 19.69 & 21.73 \\
\hline 0.655 & 0.40 & 22.99 & 19.74 & 21.87 \\
\hline 0.665 & 0.43 & 23.13 & 19.79 & 22.01 \\
\hline 0.675 & 0.45 & 23.27 & 19.84 & 22.15 \\
\hline 0.685 & 0.48 & 23.41 & 19.89 & 22.30 \\
\hline 0.695 & 0.51 & 23.55 & 19.94 & 22.45 \\
\hline 0.705 & 0.54 & 23.69 & 20.00 & 22.60 \\
\hline 0.715 & 0.57 & 23.84 & 20.05 & 22.76 \\
\hline 0.725 & 0.60 & 23.99 & 20.11 & 22.92 \\
\hline 0.735 & 0.63 & 24.14 & 20.16 & 23.09 \\
\hline 0.745 & 0.66 & 24.29 & 20.21 & 23.25 \\
\hline 0.755 & 0.69 & 24.45 & 20.27 & 23.43 \\
\hline 0.765 & 0.72 & 24.61 & 20.33 & 23.61 \\
\hline 0.775 & 0.76 & 24.78 & 20.38 & 23.79 \\
\hline 0.785 & 0.79 & 24.95 & 20.44 & 23.98 \\
\hline 0.795 & 0.82 & 25.12 & 20.50 & 24.17 \\
\hline 0.805 & 0.86 & 25.31 & 20.56 & 24.37 \\
\hline 0.815 & 0.90 & 25.48 & 20.62 & 24.58 \\
\hline 0.825 & 0.93 & 25.67 & 20.68 & 24.80 \\
\hline 0.835 & 0.97 & 25.87 & 20.74 & 25.02 \\
\hline 0.845 & 1.02 & 26.08 & 20.80 & 25.26 \\
\hline 0.855 & 1.06 & 26.29 & 20.87 & 25.50 \\
\hline 0.865 & 1.10 & 26.52 & 20.93 & 25.76 \\
\hline 0.875 & 1.15 & 26.75 & 21.00 & 26.03 \\
\hline 0.885 & 1.20 & 27.00 & 21.07 & 26.32 \\
\hline 0.895 & 1.25 & 27.27 & 21.14 & 26.62 \\
\hline 0.905 & 1.31 & 27.55 & 21.21 & 26.95 \\
\hline 0.915 & 1.37 & 27.86 & 21.28 & 27.30 \\
\hline 0.925 & 1.44 & 28.20 & 21.35 & 27.68 \\
\hline 0.935 & 1.51 & 28.57 & 21.43 & 28.11 \\
\hline 0.945 & 1.60 & 28.99 & 21.51 & 28.58 \\
\hline 0.955 & 1.70 & 29.48 & 21.59 & 29.12 \\
\hline 0.965 & 1.81 & 30.06 & 21.68 & 29.77 \\
\hline 0.975 & 1.96 & 30.80 & 21.77 & 30.57 \\
\hline 0.985 & 2.17 & 31.85 & 21.87 & 31.70 \\
\hline 0.995 & 2.58 & 33.88 & 21.99 & 33.82 \\
\hline & & & \\
\hline
\end{tabular}

\section{DISCUSSION}

We have illustrated a simple heuristic approach which amateur investors can use to analyze covered call options. The method only requires specifying two parameters: the mean $(\mu)$ and standard deviation $(\sigma)$ of the stock price at the expiration date of the option $\left(X_{1}\right)$. Both parameters can be specified conservatively. In particular, $\mu$ can be derived by first assuming that the stock price will appreciate commensurate with historical averages for the market as a whole (i.e., 10-12\%), and then discounting this expected return to achieve a margin of safety. Similarly, $\sigma$ can be derived from the spread of the distribution of $X_{1}$. As an approximate shortcut, $\sigma$ can be derived by specifying a value below which $X_{1}$ is very unlikely to fall. Clearly, this will involve some guesswork, and greatly benefits by the availability of a substantial reference point such as an annual dividend yield. The calculations in question have the advantage of 
generating a direct estimate of the expected value of the return, a parameter which is not only important in its own right but is more tangible than much of the esoterica which surround options.

This method has various limitations. First, the conclusions are no better than the assumptions about $\mu$ and $\sigma$. Conservative assumptions are recommended, as are sensitivity analyses.

Second, the distribution of $\mathrm{X}_{1}$ is typically skewed rather than Gaussian (e.g., the Black-Scholes formula assumes log-normality), and also the Gaussian assumption doesn't accommodate the occasional "black swan" where the company in question experiences an unexpected event leading to immediate bankruptcy. However, distributional assumptions can be easily modified (as illustrated above), although doing so loses some of the simplicity which is intended to appeal to amateur investors.

Third, not all stocks have options, and not all of those options have a liquid market. The spread between bid and asked prices can be problematic, and advertised prices can't necessarily be realized in actual practice.

Finally, to the extent that the trades in question are profitable, these profits are likely to be classified as short-term capital gains, with corresponding tax implications.

Why might an investor consider writing covered calls? Two rationales are typically provided. First, that the writer is essentially selling insurance. For example, the option buyer might reason that the two most likely events for LB are a disaster and a significant increase in price. By purchasing the option, the buyer (for a price) can participate in the latter without risking the former. So long as the price is right, both parties in the transaction are satisfied. Selling insurance is an activity that's profitable until it isn't, which is why any particular transaction should only constitute a small portion of a diversified portfolio.

A second argument is similar to the first, in that the option buyer is engaging in a fundamentally speculative enterprise - namely, by predicting not only the direction of a stock's next move but its timing as well - and it is always better to be the house than the gambler.

An additional argument can be advanced as well. Consider the MYL 15.00 call. The call writer has a $96.7 \%$ chance to receive the maximum possible return of $11.4 \%$, and might be perfectly happy to hold MYL stock in those unusual circumstances when $\mathrm{X}_{1}<15.00$, considering it to be a bargain at that point. Why, then, should the writer of a MYL 15.00 call receive an expected return of $10.0 \%$ (and a maximum return of $11.4 \%$ with a high probability), not even to mention even higher expected returns for writing covered calls on LB?

We would argue that what the writer of a deep-in-the-money covered call receives, above and beyond any "insurance" or "speculative" value, is essentially the expected return of the market during which their funds are encumbered. In other words, the option buyer anticipates that the market will typically rise on average by approximately $10 \%$ during any 12 -month period, and must embed this within the option premium (i.e., as compensation to the writer for selling the rights to gains that the stock achieves during those 12 months). Accepting this notion, then, writing deep-in-the-money covered calls would be particularly reasonable during a time of general market overvaluation (i.e., such as the present), since the greater the overvaluation the more likely it is that the next annual return will be less than the historical average. Indeed, deep-in-the-money covered calls might serve a similar function within a portfolio as preferred 
stock and high quality bonds - that is, providing moderate returns with low volatility, with the hope of somewhat higher returns than bonds and the like.

In summary, we have described a simple method which amateur investors can use to analyze covered calls. This approach might be especially considered during a time of market overvaluation, such as the present.

\section{STRATEGIC CONSIDERATIONS}

We have previously demonstrated that investors can achieve modest excess returns by writing short-term covered call options for "mean-regressing value stocks", the operational definition of which is essentially (1) intrinsic value remains constant during the follow-up period (which in turn implies that corporate performance is stable); (2) current stock price equals intrinsic value; and (3) prices exhibit a tendency to revert toward intrinsic value [4]. The core idea is that, so long as it can be assumed that the stock price varies around a central value, writing the covered call options serves to monetize the noise in stock price, which noise has been stipulated to be economically meaningless (i.e., because intrinsic value remains constant). There is no requirement that the investor have the skill to consistently purchase stocks below their intrinsic value, and thus no contradiction with the efficient market hypothesis is implied.

We now ask whether excess returns can be achieved by writing longer-term covered calls on value stocks (of which MYL and LB are examples). Our operational assumptions are (1) the purchase price is no more than intrinsic value; and (2) the stock in question is undergoing a "bottoming process". These assumptions are similar in intention to those of the previous demonstration.

Recognizing that the performance of actual stocks is messier than an idealized description, the bottoming process is often conceptualized as an interplay between supply and demand. During stage 1, "the final drop", disgruntled sellers capitulate. Because sellers are more motivated than buyers, the price drops. The pace of the eventual price drop eventually slows, as fewer and fewer motivated sellers remain. During stage 2, "establishing the bottom", the price stabilizes at a "bottom" level which isn't precisely predictable ahead of time, where the price-sensitive nature of the buyers and the lack of motivated sellers establishes a temporary equilibrium. In stage 3 , "the initial rise" the price begins to rise, perhaps with increasing acceleration, once it is recognized that there are no more sellers at the bottom price, nor at prices slightly above the bottom, etc. In this description the stock in question need not be a value stock, and the bottom achieved by the stock price need not correspond to intrinsic value.

In practice, once the bottoming process begins investors anticipate subsequent events, and this anticipation (among others) induces perturbations from the ideal. This anticipation also implies that investors can't necessarily wait until stage 3 (i.e., the ideal entry point from both economic and technical perspectives) is definitively under way to make purchases, but instead must begin to accumulate shares during stage 2 or even during stage 1 .

With the above in mind, and using LB as an example, from 2016 through the end of 2019 the stock price dropped from 100 to 15 (approximately), transitioning from a growth stock of a company with a dynamic business model (and ownership in Bed Bath and Beyond), to a value stock, and eventually to a deep value stock of a fashion pariah. At some point all the growth investors and, indeed, everyone but deep value investors had, or were in the process of, abandoned LB, thus suggesting that at the time of this writing stage 1 might be nearing completion. Nevertheless, the bottom price has not yet been definitively established. 
This (i.e., stage 1) is the point where a deep-out-of-the money call is warranted. For example, selling a \$10 call with 8.33 in intrinsic value (and an expected return of $16 \%$ ) allows the stock price to drop significantly without affecting returns and, in essence, pays the investor to wait and observe the process of price discovery. The investor reasons that even if stage 1 hasn't reached its conclusion, and even if the market as a whole undergoes a significant correction, LB is highly unlikely to drop below the discounted price of 9.63 .

At some point stage 2 will be entered. For purposes of illustration, we assume that the price at that time is 18.33 , the bottom is near 15 , and the option chain is as in Table 2. A somewhat more aggressive near-the-money call can be written. For example, a $\$ 17.50$ call yields a discounted purchase price of 14.43 , slightly below the bottom, thus retaining a margin of safety while increasing the maximum return (i.e., to $29.6 \%$ ) by selling 3.07 in time value.

At some subsequent point stage 3 will be entered. For purposes of illustration, we assume that the price at that time is 18.33, and the option chain is as in Table 2 . At this point the expectation is that the stock is more likely to rise in price than not, and also that the investor is less concerned about protection from price drops than in taking the optimism of other market participants and monetizing it. For example, an out-of-the-money $\$ 22.50$ call generates time value in excess of $10 \%$ of the discounted purchase price, with a maximum possible gain of $43.4 \%$. Alternatively, a covered call with a shorter duration can be written, since as the expiration date moves toward the present so does the annualized rate of return.

To summarize, during stage 1 the optimal covered call is deep in the money (so long as the expected return is considered to be adequate), and maximizes intrinsic value. During stage 2 the optimal covered call is near the money, and maximizes time value. This recommendation should be interpreted conservatively, as what the investor believes to be stage 2 might instead merely be a pause in stage 1 . Reference to some external benchmark such as a well-covered dividend yield, book value, etc. is helpful. In essence, the investor should be convinced not only that the current price likely represents a bottom, but also that this bottom is a good value. During stage 3, the optimal covered call is out of the money, and yields significant time value while holding out the possibility of larger maximum returns. The underlying logic is that the investor prefers not to hold the stock at expiration until the bottom is established, at which point they can shift their focus from defense to increasing the maximum possible return. The greater the level of optimism, the higher can be the discounted purchase price, and the greater the maximum return.

When the market as a whole is significantly overvalued, investors should shift their preferences toward writing deep-in-the-money covered calls, which provide a greater margin of safety while monetizing the (probably optimistic) expectations of other market participants regarding future returns.

\section{References}

https://www.investopedia.com/terms/b/blackscholes.asp

https://en.wikipedia.org/wiki/Truncated normal distribution

https://www.investopedia.com/terms/e/efficientmarkethypothesis.asp

Samsa G. What do you do if you've been at the poker table for twenty minutes and still can't spot the sucker? Implications for individual investors. Archives of Business Research. 2018: 6(6).

DOI:http//dx.doi.org/10.14738/abr.66.4787, online 28Jun2018. 